\title{
Atypically High Reproductive Skew in a Small Wild Chimpanzee Community in a Human-Dominated Landscape
}

\author{
Maureen S. McCarthy ${ }^{a, b}$ Jack D. Lester ${ }^{a, b}$ Marie Cibot ${ }^{b-d}$ \\ Linda Vigilant $^{\mathrm{a}}$ Matthew R. McLennan ${ }^{\mathrm{b}, \mathrm{c}, \mathrm{e}}$ \\ ${ }^{a}$ Max Planck Institute for Evolutionary Anthropology, Leipzig, Germany; ${ }^{b}$ Bulindi \\ Chimpanzee and Community Project, Hoima, Uganda; ${ }^{C}$ Department of Social Sciences, \\ Faculty of Humanities and Social Sciences, Oxford Brookes University, Oxford, UK; \\ ${ }^{\mathrm{d}}$ Anicoon Vétérinaires, Ploemeur/Larmor-Plage, France; ${ }^{\mathrm{e} C e n t r e ~ f o r ~ E c o l o g y ~ a n d ~}$ \\ Conservation, University of Exeter, Cornwall, UK
}

\section{Keywords}

Pan troglodytes - Chimpanzee - Reproductive skew - Anthropogenic disturbance .

Social rank

\begin{abstract}
Social rank is positively correlated with reproductive success in numerous species, albeit demographic factors often influence those patterns. In multimale primate species, reproductive skew tends to decrease with increasing numbers of males and sexually receptive females. Alpha male chimpanzees (Pan troglodytes) often sire a disproportionate, though somewhat variable, percentage of offspring compared to other males. In a small community of eastern chimpanzees inhabiting a human-dominated landscape in Bulindi, Uganda, we found extraordinarily high levels of alpha male reproductive success over a 5 -year period $(7 / 8$ offspring $=88 \%)$, despite the presence of multiple subordinate males. The skew exceeds that reported in other studies of chimpanzees as well as closely related bonobos (Pan paniscus). Our findings underscore the role of demographic and social factors in male reproductive success and also suggest that conclusions about species differences may be premature. The interaction of small community size, dispersal limitations, and male reproductive strategies like those found here may decrease genetic diversity and increase the risk of concomitant inbreeding in chimpanzee communities under strong anthropogenic pressure.

(C) 2020 The Author(s)

Published by S. Karger AG, Basel
\end{abstract}

ORCID: M.S. McCarthy: 0000-0001-8729-2023; J.D. Lester: 0000-0002-0390-9792; M. Cibot: 0000-00018652-1533; M.R. McLennan: 0000-0002-5925-1483.

karger@karger.com www.karger.com/fpr

Karger ${ }^{\prime \prime}=$
(C) 2020 The Author(s)

Published by S. Karger AG, Basel

This is an Open Access article licensed under This is an Open Access article licensed under
the Creative Commons Attribution-NonCommercial-4.0 International License (CC BY-NC) (http://www.karger.com/Services/OpenAccessLicense), applicable to the online version of the cial purposes requires written permission.
Maureen S. McCarthy

Max Planck Institute for Evolutionary Anthropology

Deutscher Platz 6

DE-04103 Leipzig (Germany)

maureen_mc@eva.mpg.de 


\section{Introduction}

Sexual selection theory predicts that males compete for access to a limited number of females [Trivers, 1972]. In many species, social rank reflects the outcomes of potentially costly competition among males, but these costs are frequently offset for high-ranking males by an increase in reproductive success [Ellis, 1995]. Nonetheless, even for dominant males high rank does not ensure complete control over reproductive opportunities. Models of reproductive skew typically focus on the demographic and social factors relevant to male reproductive success [transactional and compromise models; reviewed in Johnstone, 2000]. Demographic factors include the number of rival males and reproductive females; as these increase, the ability of the dominant male to control mating opportunities tends to decrease [Reeve et al., 1998]. In addition, social factors include the costs and benefits to dominant males of ceding opportunities to maintain group stability, garner support, or gain inclusive fitness benefits by allowing mating opportunities for subordinate males [Reeve et al., 1998]. In multimale primate species, reproductive skew typically decreases as a function of increasing numbers of males [Kutsukake and Nunn, 2006] and receptive females [Ostner et al., 2008], underscoring an important role for demographic factors in predicting the reproductive success of dominant males [Altmann, 1962].

Chimpanzees (Pan troglodytes) offer a useful opportunity to investigate how demographic and social factors are linked to male reproductive skew. They live in multimale/multifemale "communities" that vary in size from approximately 20 to 200 members [Sugiyama, 1999; Langergraber et al., 2017]. Sexually receptive females typically mate with multiple males [Takahata et al., 1996], and although female chimpanzee estrous cycles are asynchronous [Matsumoto-Oda et al., 2007], simultaneous sexual receptivity of multiple females commonly occurs [Goodall, 1986]. Males form a linear dominance hierarchy, with alpha males typically siring a disproportionate share of offspring [Boesch et al., 2006; Inoue et al., 2008; Wroblewski et al., 2009; Newton-Fisher et al., 2010]. Nonetheless, subordinate males also sire offspring, particularly through the use of strategies such as opportunistic mating and consortship [Constable et al., 2001]. In larger communities, alpha males may be able to exert relatively less control over mating opportunities, especially in the presence of multiple simultaneously receptive females [Boesch et al., 2006]. Male reproductive success in chimpanzee communities is therefore skewed, but variably so.

In contrast, closely related bonobos (Pan paniscus) are characterized by lower rates of male aggression and relatively higher female social ranks, which could be expected to lead to lower reproductive skew as compared to chimpanzees. Intriguingly, however, two recent studies found higher levels of reproductive skew in bonobos than in chimpanzees [Surbeck et al., 2017; Ishizuka et al., 2018]. Possible explanations for this particularly high skew include maternal support of sires, female choice acting to enhance the reproductive success of desirable males, and high group cohesion leading to few opportunities for lower-ranking males to exert alternative strategies such as consortship or sneaky copulation. However, to date there are relatively few studies on male reproductive success in bonobos, and additional research is necessary to confirm that these purported species differences [Surbeck et al., 2017; Ishizuka et al., 2018] are not merely an artefact of having insufficient data to represent the range of variation present in these species.

High Male Reproductive Skew in Wild Chimpanzees
Folia Primatol 2020;91:688-696 DOI: $10.1159 / 000508609$ 
To further explore the role of demographic and social variation on patterns of reproductive skew in Pan, we studied a small community (18-22 individuals) of eastern chimpanzees (P. t. schweinfurthii) at Bulindi, Uganda. This community contained a total of 5 males and 8 females of reproductive age during the study period, making it among the smaller habituated chimpanzee study sites. These individuals live in a human-dominated landscape characterized by small, unprotected riparian forest fragments amid farms and villages [McLennan, 2013], and are further constrained by a limited and likely decreasing ability to disperse to other communities in the region [McCarthy et al., 2018]. Using behavioral and genetic data, we determined the paternity of all surviving offspring conceived and born between 2012 and 2016 to assess patterns of male reproductive success and their potential consequences for the conservation of this exemplar of a small chimpanzee community.

\section{Methods}

\section{Study Area and Subjects}

The Bulindi chimpanzee community inhabits a farm-forest mosaic in Hoima District, western Uganda, between the Budongo and Bugoma Forests $\left(1^{\circ} 29^{\prime} \mathrm{N}, 31^{\circ} 28^{\prime} \mathrm{E}\right)$ [McLennan, 2013]. Bulindi is one of at least nine chimpanzee communities inhabiting this human-dominated landscape, which is populated by an estimated 260 or more chimpanzees [McCarthy et al., 2015]. The Bulindi chimpanzee community was studied initially from 2006 to 2008 [McLennan and Hill, 2010]. During this time, the chimpanzees were mostly unhabituated to researcher presence [McLennan and Hill, 2010] and community size was estimated at 30 or more individuals, including 6 identified mature males, at least 8 mature females, and numerous infants and juveniles [McLennan, 2010].

Data collection resumed in 2012, and the chimpanzees were fully habituated by 2015 [Cibot et al., 2019; McLennan et al., 2019]. During the period 2012-2016, all community members were individually identifiable and the community had declined to between 18 and 22 individuals, including a total of 5 mature males (range per year: $0-1$ adolescents and 2-3 adults, see online suppl. Table S1 for age estimates; see www.karger.com/doi/10.1159/000508609 for all online suppl. material) and a total of 8 mature females (range per year: 0-2 adolescents and 5-6 adults). Although precise maturational transitions are difficult to pinpoint in chimpanzees [Alberts, 2012], reproductive maturity typically occurs around age 10 and is generally defined by the onset of adult-sized sexual swellings in females and by the descent of the testes in males [Boesch and Boesch-Achermann, 2000]. This age also corresponds to the youngest age at which a wild male chimpanzee has been known to sire offspring [Boesch et al., 2006].

Since the resumption of data collection in 2012, there has been a single socially dominant (alpha) male, Sylvester (SL). Based on observational data, he is thought to have achieved alpha rank around the time data collection resumed [unpublished data]. In this study, we considered all mature males as putative fathers and as competitors for reproductive access. Among females, up to 3 were sexually receptive (i.e., with a maximal swelling of the anogenital region) at any given time during the period since 2012 [McLennan et al., 2019], though female cycle data were not available continuously throughout this time.

\section{Genetic Analysis}

We collected fresh fecal samples from chimpanzees at Bulindi during 2017. We collected samples only when individual identity could be confirmed, and collected up to five samples per individual to allow us to compare genotypes and confirm identities. Samples were stored at room temperature in the field for up to 8 months using the two-step ethanol-silica method described in Nsubuga et al. [2004]. Samples were then shipped to the Max Planck Institute for Evolutionary Anthropology in Leipzig, Germany, where they were stored at $4{ }^{\circ} \mathrm{C}$ prior to extraction. DNA was extracted and amplified at 15 microsatellite loci including amelogenin, used for sex determina- 
Table 1. Paternity analysis results for offspring conceived and born during SL's alpha tenure (2012-2016)

\begin{tabular}{|c|c|c|c|c|c|c|}
\hline \multicolumn{3}{|c|}{ Offspring } & \multirow{2}{*}{$\frac{\text { Mother }}{\text { ID }}$} & \multicolumn{3}{|c|}{ Assigned father } \\
\hline ID & sex & YOB & & $\mathrm{ID}^{\mathrm{a}}$ & rank & Comp. $^{\mathrm{b}}$ \\
\hline GG & $\mathrm{F}$ & 2013 & LL & NA & beta $^{c}$ & 4 \\
\hline $\mathrm{RO}$ & $\mathrm{M}$ & 2013 & $\mathrm{MN}$ & SL & alpha & 4 \\
\hline MK & $\mathrm{M}$ & 2013 & $\mathrm{MD}$ & SL & alpha & 4 \\
\hline $\mathrm{AL}$ & $\mathrm{M}$ & 2014 & $\mathrm{TD}$ & SL & alpha & 4 \\
\hline $\mathrm{MA}^{\mathrm{d}}$ & $\mathrm{F}$ & 2016 & $\mathrm{MD}$ & SL & alpha & 4 \\
\hline KS & $\mathrm{M}$ & 2016 & $\mathrm{JM}$ & SL & alpha & 4 \\
\hline LC & $\mathrm{F}$ & 2016 & $\mathrm{MN}$ & SL & alpha & 4 \\
\hline WD & $\mathrm{F}$ & 2016 & LL & SL & alpha & 3 \\
\hline
\end{tabular}

YOB, year of birth. ${ }^{a} \mathrm{NA}$ indicates that paternity analysis did not yield a paternity assignment with $>95 \%$ confidence. ${ }^{b}$ Number of male competitors present in the Bulindi community at the approximate date of conception. ${ }^{\mathrm{c}}$ Rank is beta if KT, the only unsampled male who was present in the community at the time of conception, was confirmed as father. ${ }^{\mathrm{d}}$ This paternity was published previously in Cibot et al. [2019].

tion [Bradley et al., 2001]. Further details of these methods are provided in the online supplementary material.

We supplemented these genotypes with additional genotype data generated from samples collected during 2012-2013 for members of this community using the same approach [McCarthy et al., 2015]. These additional genotypes provided the only genetic data for 3 individuals deceased at the time of sample collection in 2017, and provided data used to create consensus genotypes for 14 additional chimpanzees. The resulting consensus genotypes were $97 \%$ complete for 25 chimpanzees, including 8 offspring conceived and born between 2012 and 2016, 4 candidate fathers, and 8 candidate mothers. Candidate parents included all individuals who appeared reproductively mature during the study period.

\section{Parentage Analysis}

We conducted parentage analyses using a likelihood-based method in CERVUS 3.0.7 [Kalinowski et al., 2007]. First we conducted a maternity analysis to confirm all pedigree-assigned maternities, i.e., to verify mother-offspring pairs known through years of observed behavioral association. This analysis included 8 candidate mothers, all of which were sampled, and confirmed maternities for all 8 offspring with $>99 \%$ confidence.

Next we conducted a paternity analysis for the same offspring using mothers confirmed in the maternity analysis. We estimated a total of 6 candidate fathers, which included 4 sampled mature males (estimated proportion sampled $=0.67$ ), 1 mature male who was known to be present during this period but disappeared before being sampled (KT), and 1 additional potential sire via extragroup copulation. Extragroup copulation occurs infrequently in eastern chimpanzees $[<5 \%$; Wroblewski et al., 2009] and is probably especially unlikely given the lack of neighboring chimpanzee communities near Bulindi (the minimum distance to the nearest community is about $8 \mathrm{~km}$ across a human-dominated landscape), but we conservatively factored in the potential for its occurrence. All resulting paternities were assigned with $>99 \%$ confidence. Paternity for 1 offspring was published previously [Cibot et al., 2019], while all remaining paternities were newly assigned in the current study. Further details of the maternity and paternity analyses are provided in the online supplementary material. We compared reproductive skew at Bulindi, assessed as the proportion of offspring sired by the most successful male, to published values from other studies of chimpanzees and bonobos. These studies are comparable, relying on a similar 
Fig. 1. The relationship between community size and male reproductive success across bonobo and chimpanzee sites, including this study. Data beyond the current study come from reported values or study period means extracted from the following published findings: Sugiyama et al., 1993; Gerloff et al., 1999; Constable et al., 2001; Vigilant et al., 2001; Inoue et al., 2008; Newton-Fisher et al., 2010; Surbeck et al., 2017; Surbeck, personal communication.

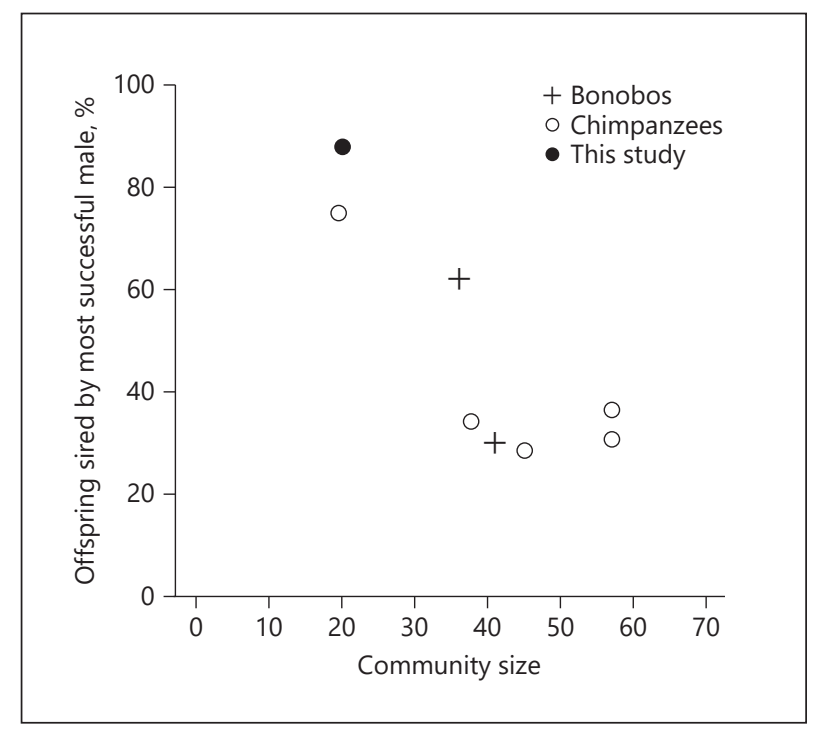

age criterion for defining male sexual maturity: 10 years in the current study and 9-10 years in the other published studies, except for one study that did not report the minimum age for male inclusion [Gerloff et al., 1999].

In addition to the paternity analysis for these 8 offspring, we conducted a second parentage analysis for 7 offspring born between 2005 and 2011, which included all surviving offspring born around and following the time the initial study of the Bulindi chimpanzees began, but prior to SL achieving alpha status. Due to the decline in community size over the course of this period, a number of candidate parents were no longer present in the community by the time of sampling in 2017 . The estimated proportions of candidate parents sampled were therefore much lower for this period (0.6 and 0.3 for candidate mothers and fathers, respectively). Because of these differences in the parentage analysis parameters, we tested this period separately to determine whether any paternities could be confirmed even in the absence of more extensive data on male ranks and full community demography. Details of this secondary analysis are provided in the online supplementary material.

\section{Results}

Of the 8 sampled offspring born since SL achieved alpha status, he sired 7 (Table 1). For the 8 th offspring, paternity could not be assigned and the father is presumed to be high-ranking KT, the only mature male who was present in the community but not genotyped during the study period. One additional offspring was born during this period, but died before being genotyped. Based on these data, alpha male SL sired $88 \%$ of the sampled offspring. Including the unsampled offspring, he sired between 78 and $89 \%$ of all offspring born since achieving alpha rank. This degree of alpha male reproductive success exceeds that reported for other chimpanzee study sites and equals or exceeds that reported for bonobos (Fig. 1,2).

SL was not assigned as father of any of the 7 sampled offspring born prior to 2012; instead, a minimum of 3 other males were found to have sired offspring during this time (details provided in the online supplementary material). 
Fig. 2. The relationship between the number of reproductively mature males in a community and male reproductive success across bonobo and chimpanzee sites, including this study. Data beyond the current study come from reported values or study period means extracted from the following published findings: Sugiyama et al., 1993; Gerloff et al., 1999; Constable et al., 2001; Vigilant et al., 2001; Inoue et al., 2008; Newton-Fisher et al., 2010; Surbeck et al., 2017; Ishizuka et al., 2018.

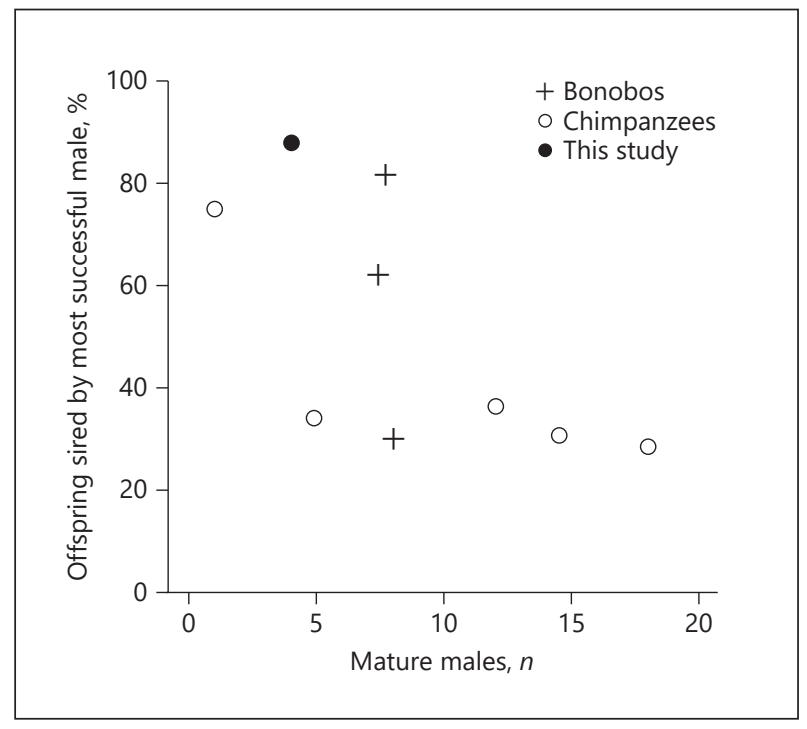

\section{Discussion}

In the small Bulindi chimpanzee community, alpha male SL sired $88 \%$ of sampled offspring during the first 5 years of his tenure. This particularly high reproductive success may have resulted from several factors. SL has frequently been observed actively mate-guarding sexually receptive females [unpublished data] and it is clear that since his alpha tenure began, SL's reproductive strategies resulted in near monopolization of paternities despite the presence of 3-4 mature males at the time of each offspring's conception. SL's reproductive control may have been aided by high community cohesion at Bulindi [unpublished data], leaving reduced chances for sneaky copulation by subordinate males. Although calculating male reproductive success is prone to stochastic variation based on sample size and the temporal window of analysis, our 5-year study period approximates the average tenure length for alpha male chimpanzees (e.g., mean $=5.4$ years) [Bray et al., 2016], making it adequate for comparisons with other studies of alpha male reproductive patterns.

This finding extends a broader pattern observed across numerous chimpanzee study sites, whereby the number of male competitors (and, more broadly, community size) is negatively associated with the alpha male's share of sirings (Fig. 1, 2). Similarly, Boesch et al. [2006] found support for the role of demographic factors in reproductive skew. In their study, as in ours, a decrease in community size was associated with an increase in alpha male reproductive success. Though limited paternity data were available for Bulindi from 2005 to 2011 as community size declined, we confirmed that at least 3 males sired offspring during this time, suggesting a shift in patterns of reproductive success with declining size.

We also found that reproductive skew was higher than levels reported at bonobo study sites. Despite recent findings indicating that bonobos have higher reproductive skew than chimpanzees [Surbeck et al., 2017; Ishizuka et al., 2018], we confirmed the 
potential for very high reproductive skew in a small chimpanzee community. Thus, our findings suggest that it may be premature to conclude that reproductive skew is generally higher in bonobos than chimpanzees, and that more data from a larger sample of bonobo and chimpanzee communities under various demographic conditions are needed to ascertain whether a species difference exists in reproductive skew.

These results have strong conservation implications for the Bulindi chimpanzee community and others like it. Genetic diversity in a wild animal population can decrease when the number of individuals reproducing decreases [Frankham, 1996], and Bulindi has experienced sharp declines in community size, with approximately onethird of the members disappearing between 2008 and 2012, including disappearances associated with anthropogenic factors [unpublished data]. Though chimpanzees are not usually hunted for meat in Uganda, increasing human pressure including habitat loss [Junker et al., 2012], snare hunting [Reynolds, 2005], crop protection methods [McLennan et al., 2012], and anthropogenic disease transmission [Scully et al., 2018] pose a serious threat to their survival. In human-disturbed habitats like this one, reduced population size can also result in inbreeding depression [Keller and Waller, 2002], and this threat can be compounded by reproductive strategies leading to an even higher level of male reproductive skew, as illustrated by our findings. Further, dispersal is a potential means of reducing the risk of inbreeding [Pusey, 1987], but habitat loss may decrease the likelihood of female dispersal [McCarthy et al., 2018], thereby heightening inbreeding risk. Given the tendency for great apes to inhabit increasingly human-altered habitats [Hockings et al., 2015], there is great practical value in understanding how demographic changes, reproductive strategies, and dispersal patterns may interact to influence genetic diversity in remaining populations. Conservation approaches can be best informed by considering the potential relationships among these factors amidst the backdrop of rapidly changing great ape habitats.

\section{Acknowledgements}

We thank Tom Sabiiti and Moses Ssemahunge for field assistance, and acknowledge the extensive contributions of the late Jacqueline Rohen to this work. This research was supported in part by the Max Planck Society. Research approval and permission to export samples was given by the Uganda National Council for Science and Technology, the President's Office, and the Uganda Wildlife Authority. We thank two anonymous reviewers for helpful comments on an earlier version of the manuscript.

\section{Statement of Ethics}

The data presented in this study were collected entirely noninvasively and required no contact with the study subjects. The study was approved by the Uganda Wildlife Authority and the Uganda National Council for Science and Technology.

\section{Conflict of Interest Statement}

The authors have no conflict of interest to declare. 


\section{Funding Sources}

This research was supported in part by the Max Planck Society.

\section{Author Contributions}

M.S. McCarthy performed laboratory analyses, analyzed the data, and wrote the manuscript. J.D. Lester performed laboratory analyses and assisted in data analysis. M. Cibot collected samples and data for analysis and contributed to project conception. L. Vigilant oversaw genetic analysis and provided expertise in the study design and analysis. M.R. McLennan collected and exported samples and data for analysis, supervised field data collection, and contributed to project conception. All authors contributed to manuscript revisions and approved the submitted version.

\section{References}

Alberts SC (2012). Magnitude and sources of variation in male reproductive performance. In The Evolution of Primate Societies (Mitani JC, Call J, Kappeler PM, Palombit RA, Silk JB, eds.), pp 412-431. Chicago, University of Chicago Press.

Altmann SA (1962). A field study of the sociology of rhesus monkeys, Macaca mulatta. Annals of the New York Academy of Science 102: 338-435.

Boesch C, Boesch-Achermann H (2000). The Chimpanzees of the Taï Forest. New York, Oxford University Press.

Boesch C, Kohou G, Néné H, Vigilant L (2006). Male competition and paternity in wild chimpanzees of the Tai forest. American Journal of Physical Anthropology 130: 103-115.

Bradley BJ, Chambers KE, Vigilant L (2001). Accurate DNA-based sex identification of apes using noninvasive samples. Conservation Biology 2: 179-181.

Bray J, Pusey AE, Gilby IC (2016). Incomplete control and concessions explain mating skew in male chimpanzees. Proceedings of the Royal Society B: Biological Sciences 283: 20162071

Cibot M, McCarthy MS, Lester JD, Vigilant L, Sabiiti T, McLennan MR (2019). Infant carrying by a wild chimpanzee father at Bulindi, Uganda. Primates 60: 333-338.

Constable JL, Ashley MV, Goodall J, Pusey AE (2001). Noninvasive paternity assignment in Gombe chimpanzees. Molecular Ecology 10: 1279-1300.

Ellis L (1995). Dominance and reproductive success among nonhuman animals: a cross-species comparison. Ethology and Sociobiology 16: 257-333.

Frankham R (1996). Relationship of genetic variation to population size in wildlife. Conservation Biology 10: $1500-1508$.

Gerloff U, Hurtung B, Fruth B, Hohmann G, Tautz D (1999). Intracommunity relationships, dispersal pattern and paternity success in a wild living community of bonobos (Pan paniscus) determined from DNA analysis of faecal samples. Proceedings of the Royal Society B: Biological Sciences 266: 1189-1195.

Goodall J (1986). The Chimpanzees of Gombe: Patterns of Behaviour. Cambridge, MA, Harvard University Press.

Hockings KJ, McLennan MR, Carvalho S, Ancrenaz M, Bobe R, Byrne RW, et al. (2015). Apes in the Anthropocene: flexibility and survival. Trends in Ecology and Evolution 30: 215-222.

Inoue E, Inoue-Murayama M, Vigilant L, Takenaka O, Nishida T (2008). Relatedness in wild chimpanzees: influence of paternity, male philopatry, and demographic factors. American Journal of Physical Anthropology 137: 256-262.

Ishizuka S, Kawamoto Y, Sakamaki T, Tokuyama N, Toda K, Okamura H, et al. (2018). Paternity and kin structure among neighbouring groups in wild bonobos at Wamba. Royal Society Open Science 5: 171006.

Johnstone RA (2000). Models of reproductive skew: a review and synthesis. Ethology 106: 5-26.

Junker J, Blake S, Boesch C, Campbell G, Toit LD, Duvall C, et al. (2012). Recent decline in suitable environmental conditions for African great apes. Diversity and Distributions 18: 1077-1091.

Kalinowski ST, Taper ML, Marshall TC (2007). Revising how the computer program CERVUS accommodates genotyping error increases success in paternity assignment. Molecular Ecology 16: 10991106.

High Male Reproductive Skew in Wild 
Keller LF, Waller DM (2002). Inbreeding effects in wild populations. Trends in Ecology and Evolution 17: 230-241.

Kutsukake N, Nunn CL (2006). Comparative tests of reproductive skew in male primates: the roles of demographic factors and incomplete control. Behavioral Ecology and Sociobiology 60: 695-706.

Langergraber KE, Watts DP, Vigilant L, Mitani JC (2017). Group augmentation, collective action, and territorial boundary patrols by male chimpanzees. Proceedings of the National Academy of Sciences of the United States of America 114: 7337-7342.

Matsumoto-Oda A, Hamai M, Hayaki H, Hosaka K, Hunt KD, Kasuya E, et al. (2007). Estrus cycle asynchrony in wild female chimpanzees, Pan troglodytes schweinfurthii. Behavioral Ecology and Sociobiology 61: 661-668.

McCarthy MS, Lester JD, Howe EJ, Arandjelovic M, Stanford CB, Vigilant L (2015). Genetic censusing identifies an unexpectedly sizeable population of an endangered large mammal in a fragmented forest landscape. BMC Ecology 15: 21.

McCarthy MS, Lester JD, Langergraber KE, Stanford CB, Vigilant L (2018). Genetic analysis suggests dispersal among chimpanzees in a fragmented forest landscape in Uganda. American Journal of Primatology 80: e22902.

McLennan MR (2010). Chimpanzee ecology and interactions with people in an unprotected human-dominated landscape at Bulindi, western Uganda. Doctoral dissertation, Oxford Brookes University, UK.

McLennan MR (2013). Diet and feeding ecology of chimpanzees (Pan troglodytes) in Bulindi, Uganda: foraging strategies at the forest-farm interface. International Journal of Primatology 34: 585-614.

McLennan MR, Hill CM (2010). Chimpanzee responses to researchers in a disturbed forest-farm mosaic at Bulindi, western Uganda. American Journal of Primatology 72: 907-918.

McLennan MR, Howell CP, Bardi M, Heistermann M (2019). Are human-dominated landscapes stressful for wild chimpanzees (Pan troglodytes)? Biological Conservation 233: 73-82.

McLennan MR, Hyeroba D, Asiimwe C, Reynolds V, Wallis J (2012). Chimpanzees in mantraps: lethal crop protection and conservation in Uganda. Oryx 46: 598-603.

Newton-Fisher NE, Thompson ME, Reynolds V, Boesch C, Vigilant L (2010). Paternity and social rank in wild chimpanzees (Pan troglodytes) from the Budongo Forest, Uganda. American Journal of Physical Anthropology 142: 417-428.

Nsubuga A, Robbins MM, Roeder AD, Morin PA, Boesch C, Vigilant L (2004). Factors affecting the amount of genomic DNA extracted from ape faeces and the identification of an improved sample storage method. Molecular Ecology 13: 2089-2094.

Ostner J, Nunn CL, Schülke O (2008). Female reproductive synchrony predicts skewed paternity across primates. Behavioral Ecology 19: 1150-1158.

Pusey AE (1987). Sex-biased dispersal and inbreeding avoidance in birds and mammals. Trends in Ecology and Evolution 2: 295-299.

Reeve HK, Emlen ST, Keller L (1998). Reproductive sharing in animal societies: reproductive incentives or incomplete control by dominant breeders? Behavioral Ecology 9: 267-278.

Reynolds V (2005). Chimpanzees of the Budongo Forest. New York, Oxford University Press.

Scully EJ, Basnet S, Wrangham RW, Muller MN, Otali E, Hyeroba D, et al. (2018). Lethal respiratory disease associated with human rhinovirus $\mathrm{C}$ in wild chimpanzees, Uganda, 2013. Emerging Infectious Diseases 24: 267-274.

Sugiyama Y (1999). Socioecological factors of male chimpanzee migration at Bossou, Guinea. Primates 40: 61-68.

Sugiyama Y, Kawamoto S, Takenaka O, Kumazaki K, Miwa N (1993). Paternity discrimination and intergroup relationships of chimpanzees at Bossou. Primates 34: 545-552.

Surbeck M, Langergraber KE, Fruth B, Vigilant L, Hohmann G (2017). Male reproductive skew is higher in bonobos than chimpanzees. Current Biology 27: R623-R641.

Takahata Y, Ihobe H, Idani G (1996). Comparing copulations of chimpanzees and bonobos: do females exhibit proceptivity or receptivity? In Great Ape Societies (McGrew WC, Marchant LF, Nishida T, eds.), pp 146-156. Cambridge, Cambridge University Press.

Trivers RL (1972). Parental investment and sexual selection. In Sexual Selection and the Descent of Man (Campbell B, ed.), pp 52-95. Chicago, Aldine Publishing Company.

Vigilant L, Hofreiter M, Siedel H, Boesch C (2001). Paternity and relatedness in wild chimpanzee communities. Proceedings of the National Academy of Sciences of the United States of America 98: 1289012895.

Wroblewski EE, Murray CM, Keele BF, Schumacher-Stankey JC, Hahn BH, Pusey AE (2009). Male dominance rank and reproductive success in chimpanzees, Pan troglodytes schweinfurthii. Animal Behaviour 77: 873-885. 